\title{
POSSIBILITIES OF BELZONA ADHESIVE JOINTS APPLICATION FOR AUSTENITIC STEEL USED IN SHIP CONSTRUCTIONS
}

\author{
Wojciech Jurczak', Kamil Jurczak ${ }^{1}$ \\ 1 Polish Naval Academy, Śmidowicza 69 Str., 81-127 Gdynia, Poland, e-mail: w.jurczak@amw.gdynia.pl, \\ kamil.jurczak1993@wp.pl
}

Received: 2017.10.24

Accepted: 2017.11.01

Published: 2017.12 .05

\begin{abstract}
This paper presents the results of research on adhesive joints durability properties of ship austenitic steel done with the use of the latest adhesives - glues: a composite one from Belzona company, described as 1111 and 1212 as well as a Hysol 9466 adhesive, produced by Hysol. The 1.4301 (304) and 1.3964 (2xx) steels used for shipbuilding were single-lap adhesive joint, with varying degree of edges' chamfering and offsetting (with a deflection). This type of alternative connections will provide protection and temporary structure's protection in case of emergency cracking (due to corrosion or an impact) of the examined steel or welded joints of the ship's construction and hull's sheathings. The adhesive joints of the tested steel were made in laboratory conditions (according to the technological card) as well as outside the laboratory, hereinafter called as the emergency ones with the use of Belzon 1212. Adhesive joints of 304 and 2xx steel using Hysol 9466 adhesive made in laboratory conditions showed better durability properties than the ones made with the use of Belzona 1111 composite. However, in case of emergency connections the bonding strength as well as the bonding time (hardening) are important factors. The use of the special Belzona 1212 (for wet surfaces) gives a relatively good durability of approx. 20MPa with a much shorter (up to $20 \mathrm{~min}$ utes) hardening time and does not require such an accurate surface preparation as the adhesive joints made with the use of Hysol 9466.
\end{abstract}

Keywords: austenitic steel, adhesive joints, shipbuilding, Hysol, Belzona.

\section{INTRODUCTION}

Adhesive joints is an inseparable mechanical connection of construction materials by means of an intermediate material called adhesive, which properties define the joint's type as moving or resting [1]. It involves spreading of an adhesive's thin layer on a previously prepared surface, filling the unevenness, which after joining the target elements, forms a narrow bonding strip called an adhesive bond. Adhesive joints is a modern technology of joining machinery components, low and medium loaded constructions but also bridges and building structures [2]. It is also used for temporary and, in justified cases, long-term emergency ruptures' connections (e.g. welded) of machine elements or other constructions. The advantage of these joints consists of taking advantage of the joined steel full durability because the adhesive layer causes no stress in the material and does not weaken the connected parts. In addition, adhesive does not affect the surface and its structure, allows the steady stresses distribution across the joint's entire area, which is corrosion-resistant and has the ability to dampen the vibrations and retain the tightness of the joint [3].

Adhesive joints are rarely used in shipbuilding due to the necessity of detailed (almost laboratory) preparation of the surfaces for adhesive bonding. The main use of adhesive joints, ac- 
cording to the literature, is to reinforce the joints of machine parts, rarely for gluing the structural components. Adhesive joints is a technology that supports riveted or threaded joints, isolating and damping the vibration of the jointed construction elements $[4,5]$.

However, due to the wide range of Belzona composite adhesives' application, also in marine conditions (elevated humidity) and exploitation (high temperature and pressure of ship's installation operating medium), it is also dedicated for emergency or preventive cracking gluing to maintain the continuity of operation of the mechanism or structure. Additionally, in such situations, the advantages of adhesive joints, which keep tightness, are corrosion resistant and minimalize vibration transmission are used.

The surface condition of austenitic steel used in laboratory tests was obtained with the simplest method - using P 320 sandpaper. For relatively hard steel HB 298-498, it was necessary to precede the mechanical preparation using a portable grinder. The removal of oxides and contaminations from the surface just prior to gluing was performed using chemical cleaning with Loctite 7063 degreasing agent. For the gluing two types of adhesives were selected - Belzona and Loctite, and the bonding processes were performed in accordance with the optimum conditions described in their technological cards. Experimentally, a series of emergency glue joints were made, for which the bonding surfaces were prepared with the use of materials and mechanical devices available on the ship. The time required to achieve the full joints durability properties, due to their future emergency use, must be as short as possible to successfully seal corrosion cracks in welded joints of 1.4301 and 1.3964 steel. Adhesives were expected to have relatively short hardening and bonding times as well as assure quick surface preparation in high humidity conditions.

\section{CHARACTERISTICS OF THE SURFACE LAYER}

In the case of constructional materials, the utility properties of their top layer are obtained by the proper selection of materials and technological processes. This selection results from the phenomenological relationships between the technological process' parameters and the resulting surface layer condition. The state of the surface layer determines the free energy of the solid's surface, which has a significant impact on the adhesive joint's quality $[5,6]$.

The state of the surface layer may be characterized by a set of surface geometry parameters (SGPs) which values depend on the steel properties and the conditions of this layer's formation (Fig. 1). Properly formed adhesive joints elements' top layer, obtained with the "drop" method, as a result of the final machinery treatment and exploitation processes, provides maximum surface durability and therefore long exploitation indestructibility of the analyzed connection $[7,8]$.

Abbott-Firestone curve or load capacity curve describe the structure of the steel surface to adhesive. The curve can be determined from the profile by drawing the parallel lines to the reference line and measuring the part of the line that fits in the profile (tab.1). The load capacity curve is related to surface roughness parameters such as $R_{k}, R_{p k}, R_{v k}$.

Generally it can be stated that the surface characteristics based on one altitude parameter $\left(R_{a}\right)$ or even aon a few such parameters $\left(R_{a}, R_{q}, R_{z}, R_{t}\right)$, is far from sufficient. For example, the predictability of the adhesive connection's durability must further take into account the amplitude and hybrid parameters $\left(R_{s k}, R_{k u}, R_{d q}\right)$ as well as the directionality of the traces and surface structure, which require 3D measurements $\left(S_{t d}, S_{a l}\right)$. There is no way to correlate SGP parameters with functional surface features so that the individual properties can be predicted on the basis of the first ones.

The study was carried out after surface preparation for adhesive joints by abrasive-mechanical treatment using a P320 grit tool (abrasive paper). Then the chemical treatment with Loctite 7063 and Belzona 9111 degreasers was applied.

Analyzing the SGP for the surface of the steel plate prepared for adhesive with a highspeed grinder, it can be stated that it is a oneway periodic surface, which can be seen in the $3 \mathrm{D}$ view of the surface. Based on the AbbottFirestone curve, it can also be noted that it is an anisotropic random surface. The biggest surface bearing ratio occurs at a depth of about $-1.8 \mu \mathrm{m}$ for 304 and -5.2 for $2 \mathrm{xx}$ steel below the average surface. The profile graph shows a large number of elevations and recesses that range from: $-1.8 \mu \mathrm{m}$ below the average to $1.2 \mu \mathrm{m}$ above the average for 304 and $-5.2 \mu \mathrm{m}$ to $3 \mu \mathrm{m}$ for $2 \mathrm{xx}$. Based on Table 1 the conclusion can be made that the surface is characterized by a negative skewness $S_{\text {sk }}=-0.599$ for 304 steel and -1.78 for $2 x x$ steel and concentration of order $\mathrm{S}_{\mathrm{ku}}=4.3$ for 304 
a)

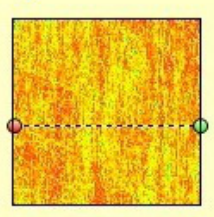

Extracted profile

b)

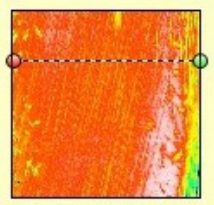

Extracted profile
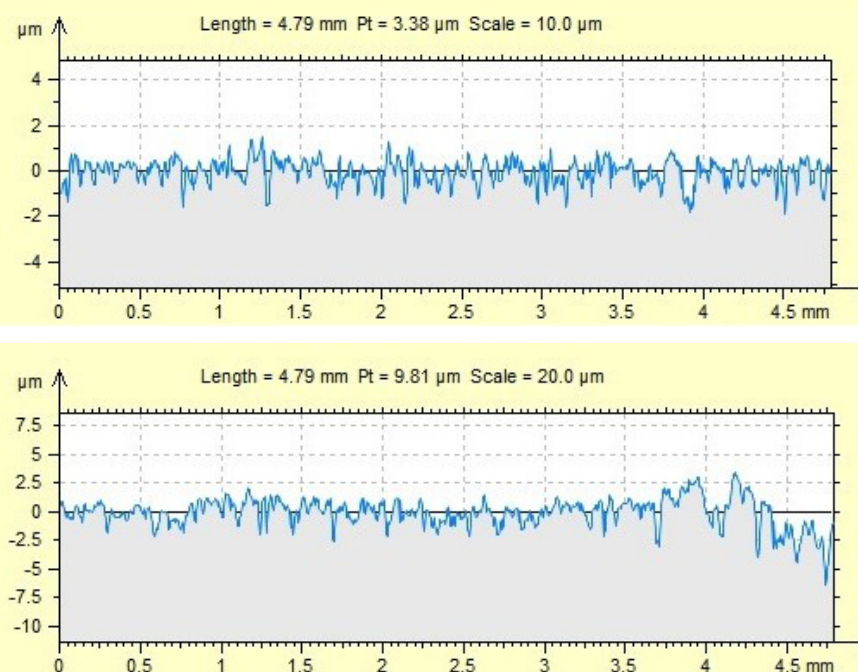

Fig. 1. Condition of the sample's surface - unevenness profile determined by austenitic steel roughness parameters: a) $1.4301(304)$, b) $1.3964(2 \mathrm{xx})$ prepared for adhesive

Table 1. Summary of selected surface roughness parameters: a) steel bearing area curves, so called Abbott - Firestone curves with marked profile elevations, b) tabled 3D parameters for steel 304 and 2xx surface conditions for adhesive

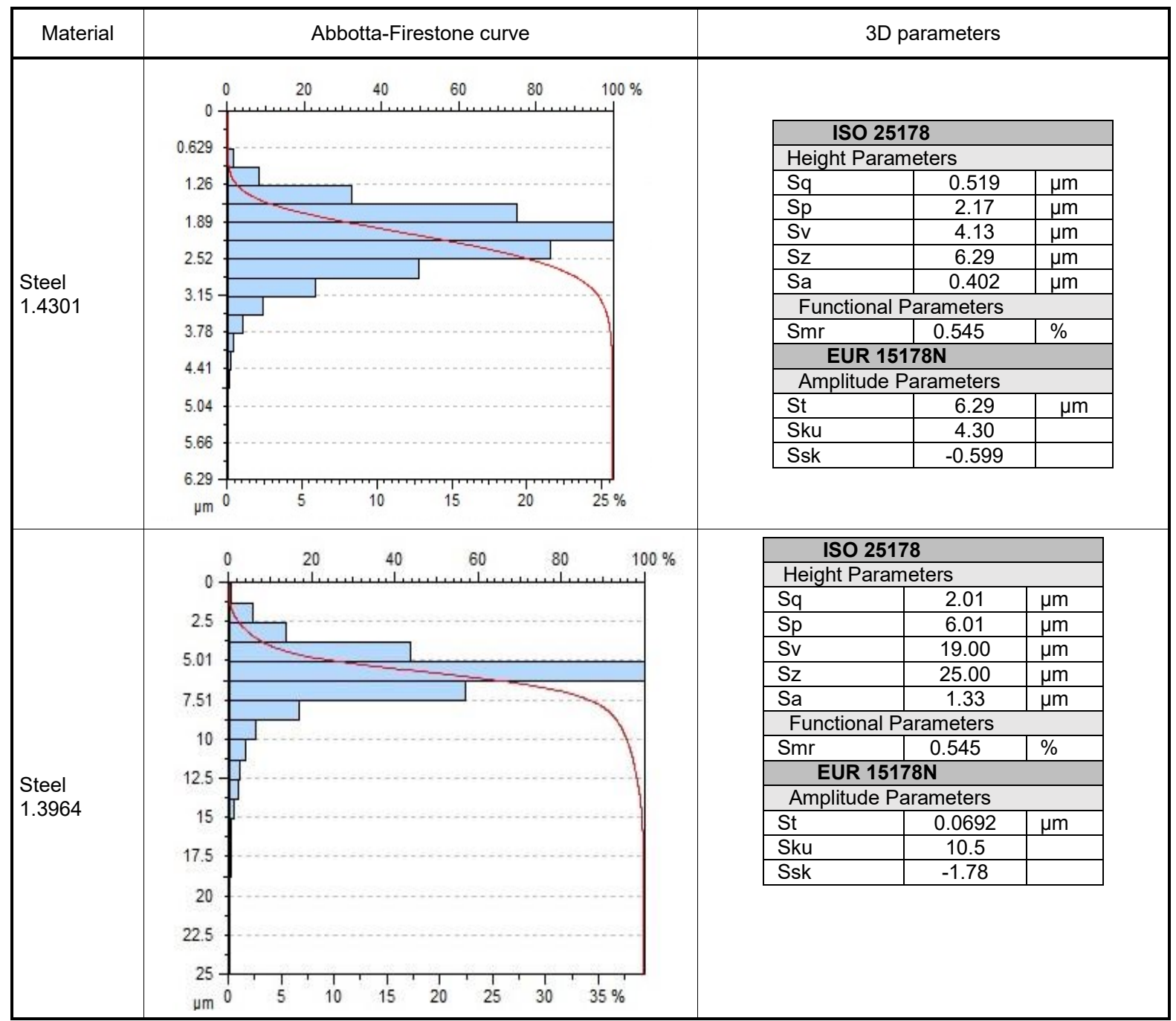


steel and 10.5 for $2 \mathrm{xx}$ steel. Waviness contribution in SGP is $\mathrm{S}_{\mathrm{al}}=0.0402 \mathrm{~mm}$ and the roughness is $S_{a}=0.402$ for 304 steel and 1.33 for $2 x x$ steel.

\section{SAMPLES SHAPES AND DIMENSIONS}

For adhesive joints samples measuring $25 \times 100$ [mm], according to PN-EN 2243-1:2006 standard, were prepared. Samples single-lap adhesive joints without (a) and with different degree of chamfering $(b, c)$ and offset $(d)$ were shown on Fig. 2

\section{ANALYSIS RESULTS}

Shear strength analysis of single-lap adhesive joints were carried out on a Zwick / Roell Z 150 durability testing machine in accordance with DIN EN 1465. The traverse speed during the destructive test was $2 \mathrm{~mm} /$ minute and the distance of the handles at the starting position was $85 \mathrm{~mm}$.

The exemplary full test reports according to shear analysis by static stretching were shown in the following graphs for selected samples of ad-

a)

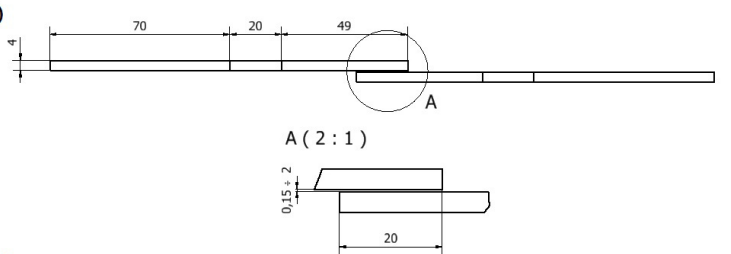

b)

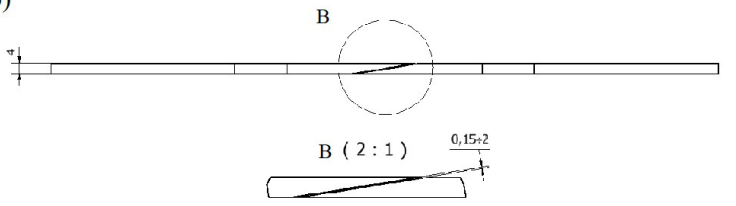

c)
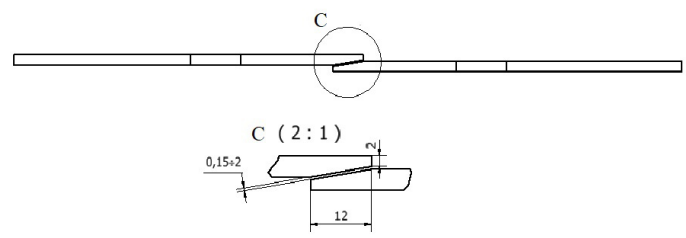

d)

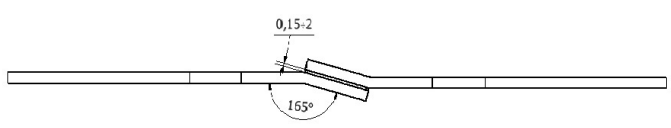

Figure 2. Dimensions of overlapping adhesive connection for four different joining shapes:

a) simple single-lap joint, b) simple single-lap, chamfered joint without edges, c) simple single-lap, chamfered joint with edge, d) simple single-lap joint with offset. hesive 304 steel joints with Belzona 1111 composite (Fig. 3) and Hysol 9466 epoxy adhesive (Fig. 4). One measurement point happen to have three samples. The graphs below show the dependence of the shear stress $\sigma[\mathrm{MPa}]$ from the elongation (deformation) $\Delta \mathrm{x}[\mathrm{mm}]$.

For chamfered joint with edge (Fig. 2c) of the tested steel 1.4301, the application of Hysol 9466 gave higher destructive force (higher resistance to the stretching force) than for the Belzona 1111 composite. This force related to the bonding surface area generated shear stress $\sigma$, which for the adhesive joint with Hybrid 9466 gave a 27\% better durability then the joint made with the composite Belzona. The displacement value $-\Delta \mathrm{x}$ for both adhesive types was low and its values are: for Hysol $9466-0.93 \mathrm{~mm}$ and for Belzona1111 composite - approx. $1.2 \mathrm{~mm}$.

For chamfered joint with edge (Fig. 2c) of the tested steel 1.4301/1.3964, the application of Hysol 9466 also gave higher destructive force (higher resistance to the stretching force) than for the Belzona 1111 composite. Shear stress $\sigma$, which for the bonded Hybrid 9466 of 20MPa was obtained for $\Delta \mathrm{x}=1.25 \mathrm{~mm}$ was twice as high as for the connection obtained with the use of Belzona composite. The graph shown on Figure 3 and parameters in Table 2 show different shear stresses values due to the different bonding surface. Adhesive surface area of chamfered joint with edge (Fig. 2c) is smaller as compared to chamfered joint without edge (Fig. 2b). In this discussion it is necessary to consider also the properties of the used adhesives related to their consistency (density) and the required application thickness. The thickness of the applied Hysol on the tested steel glued surfaces was $0.15 \mathrm{~mm}$ while for the Belzona composite it was much thicker and had $2 \mathrm{~mm}$. The tested steel gluing surfaces views (Fig. 5) are unequivocal for the thick and hard Belzona composite that are visually adhesive, while for Hysol 9466 the cracking has mixed character.

The remaining test results of 1.4301 and 1.3964 adhesive joints, representing a mean of the three samples, are summarized in Table 2.

\section{DISCUSSION}

The durability of the adhesive joints depends on the properties of the jointed elements, the state of the surface prepared for adhesive, types and properties of the adhesive and the adhesive technology $[9,10]$. For the tested austenitic steel 


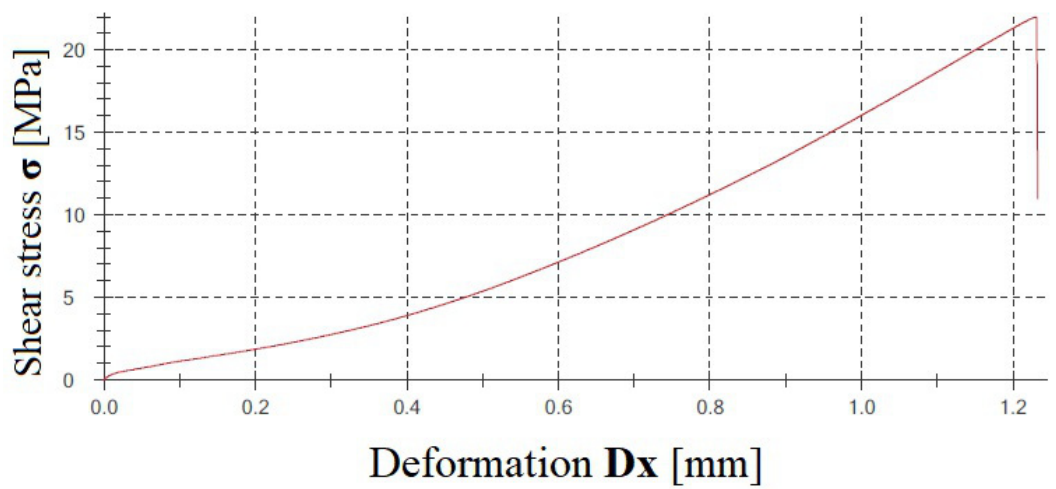

Fig. 3. Full shear analysis test report of a 1.4301 (304) austenitic stainless steel adhesive connection with Belzona 1111 composite

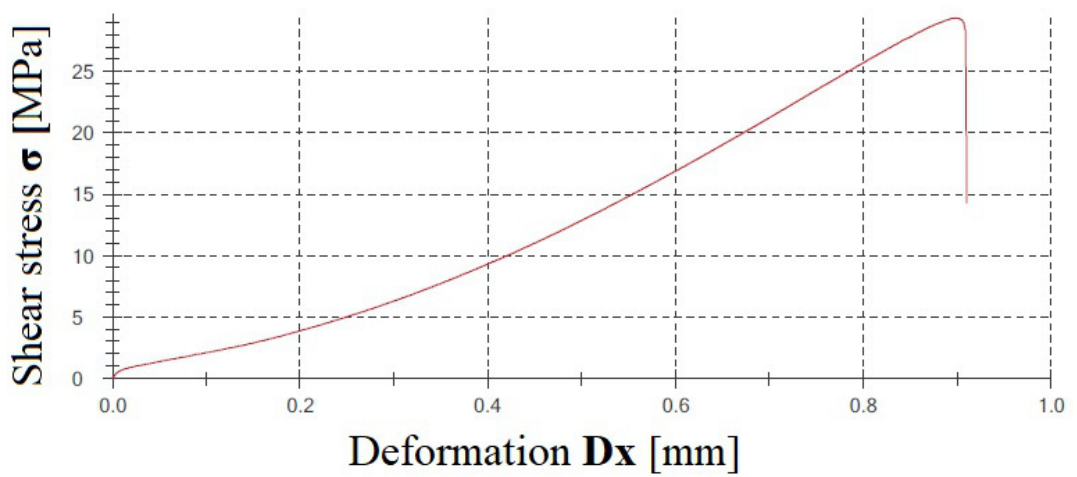

Fig. 4. Full shear analysis test report of a 1.4301 (304) austenitic stainless steel adhesive connection with Hybrid 9466

1.4301 and 1.3964 , the surface preparation was performed in laboratory conditions where, according to the technological card, adhesive joints process was carried out with the use of suitable devices.

The terms of technological bonding presented in this article indicate four successive joining stages. Preparation of the appropriate surface state as a result of sanding and grinding with P320 granular sandpaper during a 30 seconds time period is the basic stage, which was completed by surface cleaning out of contaminants and the remains of the friction elements with compressed air and then degreasing with a special solution. The type of this chemical aqueous agent depends on the type of the adhesive planned to be used. For the glue Belzona reagent was used, and for the alternative - Hysol 9466 Loctite 7061 was used. The surfaces prepared this way were dried, their condition was tested by a profilometer and the adhesive joints was carried out. The thickness of the adhesive applied, the method of its application and the time of its hardening were related to the mechanical pressure used for the joined samples, the position of the samples and the ambient temperature.

The second stage of the same steel type gluing took place outside the laboratory, where the surface preparation for adhesive joints was done by high speed grinding and the adhesive surfaces were wet. This method of adhesive joints is referred to in the article as the emergency one. It is part of the adhesive process real application in marine conditions when shipbuilding elements made of 1.4301 or 1.3964 steel suffer from cracking followed by water leak. The quick preparation of the surface, with a handy, available on the ship device (grinder), and the use of special composite adhesive Belzona 1212 is supposed to seal and assure the right durability of the connection in a short time.

Figure 3 and Table 1 show the adhesive joints durability properties of the tested steel. The resistance withstand by the adhesive joint to the axial static load was determined in a shear test on the special Zwick / Roell Z150 durability testing machines and the remaining tests on the FU1000 machine. Big differences in the mechanical prop- 
Table 2. Summary of 1.4301 and 1.3964 steel adhesive joints test results made with:

a) Belzona 1111 and Hysol 9466 adhesives, b) Belzona 1212 adhesives

a)

\begin{tabular}{|c|c|c|c|}
\hline \multicolumn{4}{|c|}{ Adhesive joins conditions - laboratory, according to the technological card } \\
\hline Steel & 1.4301 & $1.4301 / 1.3964$ & $1.4301 / 1.3964$ \\
\hline $\begin{array}{l}\text { sample type } \\
\text { sample }\end{array}$ & $\begin{array}{c}\text { chamfering with } \\
\text { edge }\end{array}$ & chamfering without edge & offset-bent \\
\hline Adhesive - Belzona 1111 & $\begin{array}{l}\sigma=11 \mathrm{MPa} \\
\Delta \mathrm{x}=1.23 \mathrm{~mm}\end{array}$ & $\begin{array}{l}\sigma=4.83 \mathrm{MPa} \\
\Delta x=1.15 \mathrm{~mm}\end{array}$ & $\begin{array}{l}\sigma=6.77 \mathrm{MPa} \\
\Delta \mathrm{x}=6.6 \mathrm{~mm}\end{array}$ \\
\hline Adhesive - Hysol 9466 & $\begin{array}{l}\sigma=14.3 \mathrm{MPa} \\
\Delta \mathrm{x}=0.91 \mathrm{~mm}\end{array}$ & $\begin{array}{l}\sigma=10.2 \mathrm{MPa} \\
\Delta \mathrm{x}=1.25 \mathrm{~mm}\end{array}$ & $\begin{array}{l}\sigma=15.9 \mathrm{MPa} \\
\Delta x=2.5 \mathrm{~mm}\end{array}$ \\
\hline
\end{tabular}

b)

\begin{tabular}{|c|c|c|c|}
\hline \multicolumn{4}{|c|}{$\begin{array}{l}\text { Adhesive conditions - outside the laboratory (emergency) in marine conditions } \\
\text { Belzona } 1212\end{array}$} \\
\hline $\begin{array}{l}\text { Sample type } \\
\text { simple single-lap }\end{array}$ & chamfered with edge & chamfered without edge & offset-bent \\
\hline $\begin{array}{l}\text { Steel } 1.3964 \\
\qquad \begin{array}{r}\sigma=18.7 \mathrm{MPa} \\
\Delta \mathrm{x}=5.3 \mathrm{~mm}\end{array}\end{array}$ & $\begin{array}{l}\sigma=9 \mathrm{MPa} \\
\Delta \mathrm{x}=8.8 \mathrm{~mm}\end{array}$ & $\begin{array}{l}\sigma=8.2 \mathrm{MPa} \\
\Delta \mathrm{x}=7.9 \mathrm{~mm}\end{array}$ & $\begin{array}{l}\sigma=19 \mathrm{MPa} \\
\Delta \mathrm{x}=29 \mathrm{~mm}\end{array}$ \\
\hline $\begin{array}{l}\text { Steel } 304 \\
\qquad \begin{aligned} \sigma=20.9 \mathrm{MPa} \\
\Delta \mathrm{X}=7.9 \mathrm{~mm}\end{aligned}\end{array}$ & $\begin{array}{l}\sigma=17 \mathrm{MPa} \\
\Delta \mathrm{X}=5.2 \mathrm{~mm}\end{array}$ & $\begin{array}{l}\sigma=6.9 \mathrm{MPa} \\
\Delta \mathrm{X}=5 \mathrm{~mm}\end{array}$ & $\begin{array}{l}\sigma=20 \mathrm{MPa} \\
\Delta \mathrm{X}=28 \mathrm{~mm}\end{array}$ \\
\hline
\end{tabular}
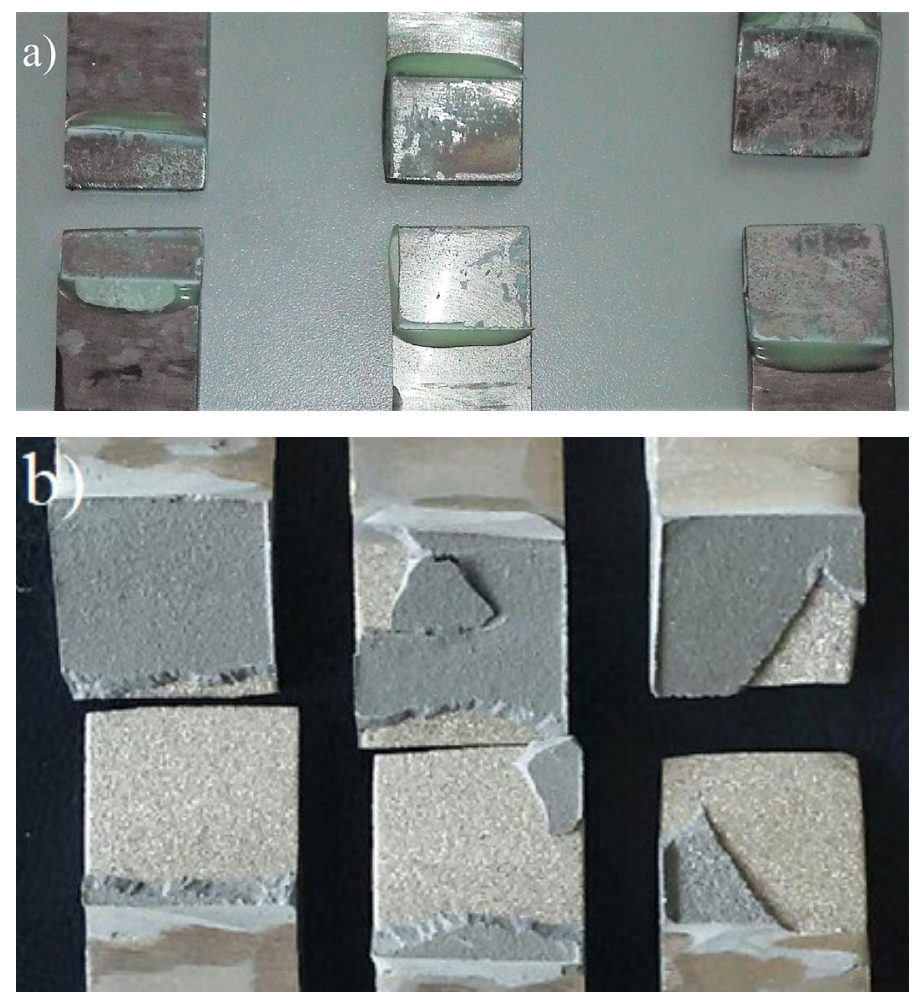

Fig. 5. Surface condition of the adhesive joints austenitic steels after technological shear test of the joints made with: a) Hysol 9466, b) Belzona 1111

erties of the adhesive steel (Table 1) and the properties of the glues used are the basis for the conclusion that the adhesive joints durability test is a test of the glue adhesion strength to the surface and of the intermolecular cohesion of the glue [8]. This means that the shear in the static stretch test is the displacement, the deformation mainly of the adhesive and in a minimum degree of the steel. It is difficult to estimate the percentage of the above mentioned phenomena in the displacement values of the tested adhesive joints, but it differs for the types of samples used (for example offset samples). To sum up, it can be said that the tested glue connections achieve 10-20\% of the strength of the adhesive joints steel, and their flexibility even considering ship's construction 
movements ensures tightness in a relatively big range (up to $6 \mathrm{~mm}$ ). Vibration suppression, fast, simple and available gluing technology possible to apply without the use of special equipment is an advantage of glued connections to other joining methods such as welding.

\section{CONCLUSIONS}

Cracking of the native shipbuilding material - austenitic steel, in particular used for mine destroyers' building may be caused by a short impact load, such as a submarine explosion and / or long-term corrosion damage arising due to its exploitation in marine conditions. One of the methods of ship structures' sealing subjected to unexpected emergency micro-cracking and in most cases accompanied by a leak is gluing. This easy and accessible bonding technology has been used for connections of 1.4301 and 1.3964 stainless steel with a selected adhesive joints, and the properties of these connections are described in the following conclusions:

1. The durability test of the steel adhesive joints shows the similar durability than the one described in the technological card for the adhesive used.

2. The surface preparation method, described by the parameters of surface geometry (Fig.1 and Tab.1) for adhesive joints and the properties of the adhesive used determine the durability of the adhesive joint.

3. In laboratory conditions, good adhesive preparation improves the quality of bonding and allows achievement of higher durability than in case of emergency gluing even when specialized adhesive (Belzona 1212) is used for glue joining of wet surfaces. Two-component epoxy adhesive Hysol 9466 offers better steel durability properties than the adhesive joints made with Belzona 1111 composite adhesive. However, twice the strength of this connection results in a threefold reduction in the susceptibility to deformation of this adhesive joint.

4. Increase of the adhesive surface and its proper shaping as described in the study (Figure 2), by different samples types has an impact on the bond durability, however, substantially influences its deformation. The offset samples (bent) obtained the best plasticity results for each type of adhesive.
5. For adhesive joints in marine exploitation conditions Belzona 1212 should be used, due to the fact that the other adhesives require a clean and dry surface.

6 . The cracking type of the tested steel connections (adhesion, cohesion or mixed) illustrates the optimum and qualitative preparation of the adhesive joint. Mixed durability is a parameter indicating the best quality of the performed bonded joint.

\section{REFERENCES}

1. Cagle C. Kleje i klejenie. Poradnik. WNT Warszawa, 2010.

2. Meinz J. Kleben in Stahlbau. Betrachtungen zum Trag - und Verformungsverhalten und zum Nachwies geklebter Trapezprofillanschlüsse und versträkter Holprofile in Pfosten_Riegel-Fassaden, Weißensee Velag, 2010.

3. Godzimirski J. Wytrzymałość doraźna konstrukcyjnych połączeń klejonych. WNT, Warszawa 2002.

4. Holmberg K., Adgar A., Arnaiz A., Jantunen E., Mascolo J., Mekid S.: E maintenance. Springer Verlag, London 2010.

5. Kłonica M., Kuczmaszewski J., Kwiatkowski M. and Ozonek J. Polyamide 6 surface layer following ozone treatment. International Journal of Adhesion and Adhesives, 64, 2016, 179-187.

6. Kwiatkowski M. P., Kłonica M., Kuczmaszewski J. and Satoh S. Comparative analysis of energetic properties of Ti6Al4V titanium and ENAW-2017A(PA6) aluminum alloy surface layers for an adhesive bonding application. Ozone: Science\&Engineering: The Journal of the International Ozone Association, 35 (3), 2013, 220-228.

7. Kłonica M., Kuczmaszewski J. Determining the value of surface free energy on the basis of the contact angle. Advances in Science and Technology Research Journal 11 (1), 2017, 66-74.

8. Kłonica M., Kuczmaszewski J., Ozonek J. Ocena porównawcza właściwości energetycznych warstwy wierzchniej stopu tytanu. Inżynieria materiałowa. Nr 5 (171) 2009 s. 396-399.

9. Komorek A. Badania trwałości zmęczeniowej połączeń klejonych. Rozprawa doktorska. Wojskowa Akademia Techniczna, 2008.

10. Kuczmaszewski J. Fundamentals of metal-metal adhesive joint design. Politechnika Lubelska. Oddział PAN w Lublinie, 2006. 